\title{
MEDICINA, SAÚDE PÚBLICA E PODER EM TEMPOS DE EPIDEMIAS (PORTUGAL - SÉCULOS XIV-XVI)
}

\section{Medicine, Public Health and Power in Epidemic Times (Portugal - XIV-XVI Centuries)}

\author{
Prof. Dr. Mário Jorge da Motta Bastos \\ Universidade Federal Fluminense - IHT - Translatio Studii - NIEP-Marx-Prék \\ Bolsista de Produtividade em Pesquisa do CNPq \\ ORCID: https://orcid.org/0000-0002-6048-8824 \\ velhomario@gmail.com
}

Recebido em: 24/09/2020

Aprovado em: 30/11/2020

\begin{abstract}
Resumo: As sociedades pré-capitalistas - problema superado? - foram atingidas por diversos cataclismos e epidemias. Entre essas, a peste se manifestou em ciclos epidêmicos frequentes desde a eclosão da grande epidemia de Peste Negra de 1348 até pelo menos fins do século XVI, promovendo súbitas e sistemáticas elevações das já elevadas taxas de mortalidade, e provocando destruição, medo e caos social. Em Portugal, houve ao menos uma epidemia a cada década ao longo do período, que atingiram especialmente as cidades portuárias, com destaque para Lisboa. A doença era um fator de desestabilização e desordem social que suscitou da realeza, poder que se pretendia ordenador, a promoção do embate por meio de ações variadas. A atuação régia relativa às epidemias articulou-se com base em dois elementos essenciais, a produção de uma caracterização da doença e a definição de iniciativas, posturas e normas voltadas à sua superação, cujo descumprimento implicava em penas físicas e pecuniárias. Neste artigo, abordaremos a ascensão de um saber médico, erudito, vinculado à tradição da medicina da Antigüidade, e veiculado nas universidades que, investido pela realeza, tornou-se o principal instrumento do poder em sua intervenção social contra o flagelo.
\end{abstract}

Palavras-chave: Portugal Medieval; Epidemias; Medicina; Poder Real.

Abstract: Pre-capitalist societies - overcome problem? - were affected by several cataclysms and epidemics. Among these, the plague manifested itself in frequent epidemic cycles from the outbreak of the great Black Death epidemic from 1348 until at least the end of the 16th century, promoting sudden and systematic increases in the already high mortality rates, and causing destruction, fear and social chaos. In Portugal, there was at least one plague every decade throughout the period, which particularly affected port cities, with emphasis on Lisbon. The disease was a factor of destabilization and social disorder which demanded from royalty, the power intended to be the ordering authority, the promotion of the shock through various actions. The royal action related to epidemics was based on two essential elements, the production of a characterization of the disease and the definition of initiatives, attitudes and norms aimed at overcoming it, whose non-compliance implied physical and pecuniary penalties. In this article, we will discuss the rise of a medical knowledge, erudite, linked to the medical tradition of Antiquity, and conveyed in universities that, invested by royalty, became the main instrument of power in its social intervention against the scourge.

Keywords: Medieval Portugal; Epidemics; Medicine; Royal Power. 
Numa obra que se tornou um clássico, até por seu pioneirismo, dedicada à História da Universidade de Coimbra e datada de fins do século XIX, Teófilo Braga celebra, no capítulo em que aborda a Faculdade de Medicina, o que definiu como o “esplendor extraordinário" vivenciado pelos estudos médicos em Portugal no século XVI. Quanto às razões de tão notável conjuntura, o autor destaca o vigor da cultura humanista, o cosmopolitismo de professores e alunos, a descoberta de novas drogas e a difusão de diferentes saberes favorecidos pela expansão ultramarina, a par da incidência de um poder político atento à mudança e à inovação (BRAGA, 1895: 768).

Manifestando sua concordância essencial com os juízos do autor, Laurinda Abreu ressalta, contudo, que, em Portugal, o aperfeiçoamento da formação dos quadros de profissionais da saúde, o processo de institucionalização das profissões do setor, bem como a experimentação de novas e modernas técnicas de intervenção e de terapêuticas não podem ser dissociados da intervenção direta da Coroa neste campo e em áreas afins. Entre essas, destacam-se a reforma dos hospitais, a criação das Misericórdias e a promulgação de legislação sanitária específica relativa às epidemias.

\footnotetext{
Em todos estes campos - caridade, assistência e saúde -, [a centúria de] quatrocentos marcou $\mathrm{o}$ arranque de profundas transformações em procedimentos que seriam consolidados ao longo da centúria seguinte, fixando então um conjunto de regulamentos, doutrinas e preceitos que poucas alterações experimentariam até boa parte do século XVIII (ABREU, 2010: 97).
}

Assim, ao mesmo tempo em que a realeza regulamentava o exercício das «artes curativas», a Coroa portuguesa organizava o campo da saúde pública especialmente devotada ao combate às epidemias, às pestilências que assolaram o reino de Portugal entre os séculos XIV e XVI, numa intensa cronologia seguida nos séculos seguintes por surtos mais espaçados e por medidas protetivas diversas que constituem a história da saúde pública em Portugal. O investimento da realeza portuguesa na normatização do exercício dos ofícios ligados ao campo da saúde, por meio de ordens, normas, leis e regimentos diversos, desde pelo menos princípios do século $\mathrm{XV}$, converge com um conjunto de ações que marcam as iniciativas voltadas à afirmação da ascendência política e da hegemonia régia no contexto em questão (BASTOS, 2009). E não foi despiciendo neste processo a incidência cotidiana de epidemias várias - de peste, em especial, em razão do novo ciclo de contágio inaugurado pela pandemia de Peste Negra 
de 1348 - que afligiram a Europa e Portugal, em especial em suas cidades portuárias, com destaque aqui para Lisboa. A doença era um fator de desestabilização e desordem social que suscitou da realeza, poder ordenador, a promoção do embate por meio de ações variadas.

A terrível pandemia de Peste Negra que, grosso modo, entre os anos de 1333 a 1352 atingiu a Ásia, a Europa e o norte da África, sobretudo, tem seus impactos e efeitos até hoje debatidos pelos historiadores. É provável que tenha sido responsável pela mais intensa crise demográfica experimentada pela humanidade em toda a sua História, ceifando as vidas de $1 / 3$ a $1 / 2$ da população das áreas atingidas, ou cerca de 50 milhões de pessoas. Ademais - aspecto por longo tempo desprezado pelos historiadores - a Peste Negra, a despeito de ímpar em sua manifestação, deu origem a um novo ciclo de contágio semelhante aquele ocorrido na Alta Idade Média, quando a "Peste de Justiniano", de princípios do século VI, deu ensejo a novas vagas epidêmicas que se repetiram até fins do século VIII.

Desde Pollitzer e Wu Lien-Teh (ROQUE, 1079, 70-85), na década de 1950, situava-se a origem da Peste Negra no extenso e primitivo foco natural da doença radicado no planalto central da Ásia, onde grassava em estado endêmico, expandindo-se daí por três vias para assumir o seu caráter de pandemia: deslocando-se para o oeste, abateu a Europa; para o sul, a Índia e, por fim, a caminho do leste, fustigou grande parte do Extremo Oriente. No entanto, estudos posteriores, levados a efeito a partir da década de 1970, estabeleceram que o foco centroasiático foi apenas coadjuvante naquela pandemia, que se teria originado na China. Com base em cronistas e informações de natureza vária, conclui-se que o deslocamento da epidemia para Ocidente fora precedido de uma longa série de catástrofes que, desde 1333, assolou diversas regiões chinesas. Alternaram-se, num período de 15 anos, secas prolongadas, chuvas torrenciais e tremores de terra que ceifaram, por si, milhões de vidas. Em última análise, tal frequência de distúrbios climáticos teria desalojado de seus focos naturais elevadas quantidades de roedores infestados de pugas e do bacilo pestífero, ainda hoje comuns na Mandchúria, Mongólia e Turquestão. Seriam eles que, ao se dispersarem, juntamente com as primeiras populações infectadas, ensejaram a disseminação da doença. Sua marcha para Ocidente seguiu as duas principais vias de comércio. 
A primeira, terrestre, cruzava o extenso - e eivado de focos naturais da doença -, planalto centro-asiático. Quer tivesse aí se originado ou reforçado, as lápides sepulcrais de diversos centros populacionais, sobretudo na Rússia, atestam a morte por peste a partir de 1338, bem como seu curso lúgubre para oeste. Por tal via, a epidemia atingiria os movimentados portos do Mar Negro, como os de Caffa e de Constantinopla, que foram dizimadas a partir de 1346 (CICCO, 2014: 15-56). A segunda via rumava da China pelo sul, cruzando a Índia, para daí, por via terrestre ou marítima respectivamente pela Pérsia e Mesopotâmia e via Golfo Pérsico e Mar Vermelho atingir os portos do Mediterrâneo oriental. Por qualquer das vias, a epidemia encontrava-se instalada nestes centros comerciais entre fins de 1346 e princípios de 1347, grassando já em Alexandria e no norte da África, nas ilhas gregas, em Jaffa, Caffa e Constantinopla. Não tardaria a abordar a Europa ocidental, ao que parece seguindo também duas rotas.

Partindo da Criméia, atravessou a Alemanha central, indo fustigar as cidades hanseáticas e as regiões bálticas e do Mar do Norte. Avançando pelo Mediterrâneo com assombrosa velocidade, em um trimestre (fins de 1347 e princípios de 1348) franqueou seus principais portos, e daí o continente. De Messina, ganhou a Sicília, Túnis, Córsega, Sardenha, Baleares e os portos orientais da Península Ibérica. Enquanto Gênova constituiu-se em principal polo difusor da peste na Itália setentrional e central, Veneza, onde a doença instalou-se a despeito da precocidade das medidas preventivas, irradiou-a para a Áustria e a Hungria. E coube a Marselha, atingida a partir de Messina, o triste lugar de destaque na difusão europeia do flagelo, que daí seguiu por três vias: para ocidente, por via marítima, contaminou a Septimânia (Narbonne, Carcassone, Toulouse etc.), atingiu a Catalunha e, por fim, seguindo o curso do Ródano, abordou o norte da França, Flandres, os Países Baixos, Bélgica e Alemanha. Na sequencia, atingiu a Inglaterra, Escócia, Irlanda e regiões escandinavas, de onde rumou para oriente, adentrando a Rússia, e completando em 1352, no Mar Negro, o périplo que tivera ali, cinco anos volvidos, um dos principais centros de disseminação (BYRNE, 2012: 28$65)$.

As tentativas de determinar o início e a progressão da epidemia de Peste Negra em terras portuguesas esbarram, até aqui, na escassez e no laconismo das fontes. O Livro da Noa, do mosteiro de Santa Cruz de Coimbra, um dos raros documentos coetâneos que 
se refere à epidemia, registra que na "Era de mil e trezentos e oytenta e seys anos [era de César, correspondendo ao ano de 1348 do calendário gregoriano] por S. Miguel de Setembro [festa em 29 deste mês] se compeçou esta pestilençia." Quanto à sua duração, afirma que "esta mortaydade duraua na terra por spaço de tres meses". Ao indicar os sintomas da doença, assegura-nos da presença da peste: "e as mays dores das doenças eram de leuacoens que tijnham nas verilhas e so os bracos", referência explícita ao bubão pestilencial (RAU, 1986: 129).

BASICAMENTE A PARTIR DESSAS INFORMAÇÕES, A HISTORIOGRAFIA PORTUGUESA (ROQUE, 1979: 124) CONCLUI QUE O INICIO DO CONTAGIO SE DEU EM FINS DE SETEMBRO DE 1348, TENDO SIDO BREVE, AINDA QUE NEFASTA, A SUA DURAÇÃO EM TERRAS LUSITANAS. MARIO DA COSTA ROQUE, NO ENTANTO, CRITICANDO A REFERENCIA LITERAL E MUITO POUCO CRITICA AOS REGISTROS ACIMA TRANSCRITOS, PÕE EM DUVIDA NÃO SO O INICIO DA EPIDEMIA POR ESTA ALTURA - TENDO EM VISTA A PARTICIPAÇÃO EFETIVA DO PAIS NO INTENSO TRAFEGO COMERCIAL MEDITERRANICO, CUJOS PRINCIPAIS PORTOS FORAM CONTAMINADOS AINDA EM FINS DE 1347 BEM COMO SUA DISSEMINAÇÃO E DESAPARECIMENTO EM APENAS TRES MESES. REDIMENSIONANDO A EXTENSÃO DAS INFORMAÇÕES CONTIDAS NO LIVRO DA NOA, CONSIDERA-AS RESTRITAS AO INICIO E DURAÇÃO DO FLAGELO NUMA "TERRA" ESPECIFICA, POSSIVELMENTE COIMBRA. ADVOGA O AUTOR QUE A ENTRADA DA PESTE EM PORTUGAL DEVE TER OCORRIDO NA PRIMAVERA DE 1348, ESTAÇÃO PROPICIA A ECLOSÃO DO SURTO ORIUNDO DO MEDITERRANEO, E QUE SUA DIFUSÃO PELO HINTERLAND TENHA SE DADO AO LONGO DESTE ANO, DE FORMA MAIS OU MENOS LENTA SEGUNDO UM TRAJETO FLUVIAL OU TERRESTRE (ROQUE, 1979: 123136).

A partir de 1348, diversas regiões do mundo então interligado, entre elas a Europa, a Península Ibérica e, para os nossos interesses aqui, mais especificamente o reino de Portugal, foram atingidas por surtos epidêmicos diversos que afligiam, em média uma vez a cada década, especialmente as cidades portuárias da fachada atlântica, 
com destaque para a já então capital e principal cidade do reino, Lisboa. Em face de tal nefasta cronologia, A. H. de Oliveira Marques nos propõe uma perspicaz reflexão:

Cada português dos séculos XIV e XV [incluiria ai, sem dúvida, o XVI] viu duas ou mais epidemias durante a sua vida, e teve, com certeza, parentes e amigos levados por elas [...]. Compreende-se assim os esforços de físicos, boticários, curandeiros, bruxos e até filósofos e políticos no sentido de se descobrirem remédios eficazes de proteção (MARQUES, 1987: 121).

O que se impôs, portanto, algo que talvez agora sejamos, lamentavelmente, capazes de dimensionar mais adequadamente, foi um convívio cotidiano e inquietante com a morte pela intervenção recorrente de um poder desestruturador da vida cotidiana e das relações sociais que a perfazem. Urgia, assim, acima de tudo, compreender a doença, traduzi-la, explicitar as suas motivações, premissa indispensável às tentativas de superá-la ou, antes, dominá-la. Em que pese a possibilidade, e certamente a existência, de apreensões diversas da moléstia, como indica o autor citado, impôs-se, no Portugal do período, uma compreensão particular da doença, emanada do poder central, que a delimitou, requisitando à realeza o poder e a função de intervenção social no sentido de sua superação. A atuação régia relativa às epidemias articulou-se com base em dois elementos essenciais, a produção de uma caracterização da doença - e aqui não se tratava apenas de promover mais um discurso possível sobre a mesma, mas daquele que se intenta impor socialmente como o discurso "qualificado" -, e a definição de iniciativas, posturas e normas voltadas à sua superação, cujo descumprimento implicava em penas físicas e pecuniárias.

Ora, o contexto marcado pela elevada incidência da doença representou para a medicina de época um enorme desafio, a par de uma efetiva oportunidade de afirmação. Como bem destacou Jacques Le Goff, “[...] a doença pertence não só à história superficial dos progressos científicos e tecnológicos como também à história profunda dos saberes e das práticas ligadas às estruturas sociais, às instituições, às representações, às mentalidades." (LE GOFF, 1991: 8) Oportunidade que foi, por sinal, decididamente explorada por seus especialistas, em que pesem as muitas resistências e os muitos revezes que enfrentaram.

Lamentavelmente, uma vez mais, o quadro que vivemos no mundo nos facilita - com uma considerável dose de estupefação - compreender que a medicina 
de então, longe de desfrutar de uma posição hegemônica de autoridade absoluta em matéria de epidemia - e, portanto, em matéria de saúde e doença dos corpos enfrentava percepções concorrentes. Destaque, entre essas, até mesmo uma deliberada objeção "popular" à sua intervenção, aparentemente reticente em relação a muitas das duras medidas propostas por "físicos" e "cirurgiões", suspeição de resto favorecida pelos elevados índices de letalidade da doença que a medicina era incapaz de confrontar.

Ainda em meio ao pânico e ao terror promovidos pela Grande Peste de 1348, vemos despontar um saber médico, erudito, vinculado à tradição da medicina da Antigüidade, e veiculado nas universidades. Pretendendo afirmar-se como um saber distinto das "opiniões supersticiosas" que dominavam as mentes, requisita para si a verdadeira compreensão da doença. Guy de Chauliac, considerado o maior expoente da medicina de sua época, estando em Avignon por ocasião da Peste Negra afirmou:

\footnotetext{
Era para muitos duvidosa a causa desta grande mortandade. Acreditou-se numas partes que os judeus tinham envenenado o mundo e matavam-nos, noutras punham a culpa aos pobres mutilados, e corriam-nos, e alguns atribuíam-na aos nobres, que não se aventuravam a sair para os seus negócios [...]. Fique-se porém o povo na sua, que a verdade foi haver duas causas desta mortandade, uma universal agente, outra particular paciente (MEIRELLES, 1866, 48).
}

A divulgação desse saber, transcendendo o meio universitário num processo de vulgarização, efetivou-se a partir da Peste Negra, atribuindo-se a iniciativa à Faculdade de Medicina de Paris, que em outubro do fatídico ano lançou o seu Compendium de Epidemia (MOLLAT, 1989, 190). Ensejava-se um gênero literário que iria se impor no Ocidente, tanto quanto se impôs a macabra presença da doença.

Inicialmente redigidos em latim, os manuais sobre a doença conheceram larga divulgação na Europa, transcendendo o recorte cronológico específico da Idade Média, deduzindo-se seu número elevado da enorme quantidade de exemplares que sobreviveram ao tempo. Vastas vezes copiados, e sujeitos, portanto, a interpretações errôneas, desvios e interpolações, "não raro um exemplar tido por original em muito se distanciara de sua fonte. Irreconhecíveis, guardavam no entanto suas bases de referência galênica." (ROQUE, 1979: 230) 
A partir do desenvolvimento da imprensa, e favorecendo-a, tais escritos conheceram mais fácil e rápida difusão, principalmente, naqueles centros populacionais europeus mais atingidos pela epidemia. Muitas tipografias deram início às suas atividades com a impressão destes manuais.

\begin{abstract}
Por iniciativa própria ou por encomenda de autoridades vigilantes da saúde pública, o negócio dos impressos contra a peste, com custos mínimos de produção e venda assegurada, era sempre rendoso. Por isso, tais impressos, produções pioneiras de um grande número de oficinas, ocupam um lugar de primazia na história da proto-imprensa européia. Assim, figuram entre os incunábulos mais primitivos, aparecem como primeiras produções de certas tipografias e ainda como os primeiros textos médicos estampados em diversos países e cidades (ROQUE, 1979: 231).
\end{abstract}

Em Portugal, o primeiro texto médico dado a estampa foi o Regimento proueitoso contra ha pestenença (JACOBI, 1962). Sua autoria coube a Johannes Jacobi, Mestre em medicina e Cancelário da Universidade de Montpellier, onde residia por ocasião da Grande Peste, e escrito em data incerta, no século XIV, provavelmente no ano de 1357. Conhecendo grande difusão na Europa medieval, em meados do século XV, uma sua versão atribuída à Kaminto ou Canuto seria traduzida ao português em Lisboa por Frei Luis de Rás, Mestre em Teologia da Ordem de S. Francisco, entre fins de 1495 e princípios de 1496. Destaque-se que essa cidade sofria, por esta altura, um ciclo endêmico de peste que a assolava desde 1480 .

Também diretamente relacionada à deflagração de um surto epidêmico viria à luz, em Portugal, a Recopilaçam das Cousas que convem guardarse no modo de preservar à Cidade de Lixboa: E os sãos, E curar os que esteuerem enfermos de Peste... (ALVARES; CORONEL, MDLXXX), obra quatro vezes editada, apenas no século XVI, datando a primeira edição de 1569, cuja autoria cabe a dois médicos provenientes de Sevilha. Segundo informação dos próprios, Thomaz Alvares e Garcia de Salzedo Coronel, foram ambos convocados por D. Sebastião à Lisboa "para q con los medicos desta Ciudad comunicasemos los remedios que este mal (peste) podia tener [...].” (ALVARES; CORONEL, MDLXXX, 2) Anunciara-se, em Lisboa, mais um dos frequentes ataques da doença, tão ou mais terrível do que poderia ter sido a Peste Negra de 1348.

Ainda em meados de janeiro de 1569 surgiram as primeiras manifestações: 
[...] começarão [...] a sintirse géralmente erisipulas e carbunculos com febres de mà calidade, que dando em $\mathrm{h}$ ua casa se pegavão e corrião por todos: logo se forão descobrindo forçãs de mayor veneno, em pintas e inchaços, com mortes arrebatadas (MEIRELLES, 1866: 43).

As autoridades e médicos concelhios, numa reação comum ao início de um surto, procuraram negar a natureza do contágio. Informa-nos o autor do Portugal Cuidadoso, e Lastimado, que a junta de médicos convocada nos Paços do Castelo por D. Sebastião para definir a origem da doença, cindiu-se em opiniões contrárias, prevalecendo inicialmente a de que não se tratava de peste, mas de uma moléstia causada pelos rigores do clima. Em fins de junho, contudo, deslocava-se a Corte para Cintra, em função do contágio que dizimava a cidade. Outras localidades do reino foram também atingidas no curso desta epidemia, como Santarém, Évora e Braga (MEIRELLES, 1866: 36).

Contra este pano de fundo impõe-se a imagem do rei responsável pela preservação da saúde do corpo social. Segundo os autores da Recopilaçam das Cousas..., é do "pecho christianissimo" do rei que nasce o "zelo [...] para el remedio deste mal de peste." (ALVARES; CORONEL, MDLXXX, 2) Imagem tal que persiste no tempo, uma vez que seria evocada ainda ao início do século XIX. Alexandre Portugal, em seu manual contra a peste, impresso em Lisboa por essa altura, afirma que se iria furtar de tratar dos meios a serem empregados no combate à doença pelas autoridades públicas, "pois que o estabelecê-lo pertence a hum Soberano piedoso e ilustrado." (PORTUGAL, 1801: IV) No processo da afirmação do "rei físico", como veremos a seguir, coube à medicina um lugar de destaque.

Segundo a medicina de época, a peste caracterizava-se pela ação de forças malignas, constituindo-se numa entidade viva, agente, que contaminava o ar, pairava sobre as cidades perseguindo a morte dos indivíduos, presas básicas em seu projeto maior de destruição: provocar a desestruturação do corpo social. Assim, a superação do mal que abatia a sociedade exigia o recurso ao "muyto bõ mantimento", aos "bõs cheiros", à "boa agoa" e ao "bõ vinho" (ALVARES; CORONEL, MDLXXX: 8), destinados à preservação da virtude e do espírito vital. Essa a dicotomia fundamental estabelecida pela medicina, norteadora da conduta e ações humanas em tempos de 
epidemia. Desponta, desse quadro, a ação restauradora do médico, conhecedor e divulgador dos caminhos e perspectivas de reordenação e reequilíbrio da sociedade abalada pela doença. Dado o seu caráter antinatural, a doença, interiorizada no corpo humano, sofria a reação da natureza, que "se rege por intelligencia que não erra" (ALVARES; CORONEL, MDLXXX: 3), que procura expurgar do organismo o veneno que lhe ofende.

A compreensão desse quadro demanda considerarmos a noção da etiologia da doença expressa pelos tratadistas medievais (ROQUE, 1979: 54). Esses, além de recorrerem frequentemente a autores coetâneos, preservam no essencial a etiologia galênica da peste, mais ou menos adequada ao que a experiência empírica impunha. Para Galeno, tal como os autores medievais o entenderam, as doenças das partes homogêneas, isto é, dos tecidos orgânicos, eram essencialmente devidas, com base nos conceitos de Pitágoras, de Alcmeon e de Empédocles, seguidos por Hipócrates, a um desequilíbrio que se verificava na combinação natural das qualidades primárias: quente, fria, seca e úmida, relacionadas com os quatro elementos (ar, água, terra e fogo) e com os quatro humores (sangue, bílis, pituíta e atrabílis). O equilíbrio entre aquelas quatro qualidades era igual à saúde. A alteração das respectivas proporções pela preponderância de umas em relação às outras conduzia à doença.

$\mathrm{Na}$ peste produzia-se, pois, um desequilíbrio entre as quantidades relativas daquelas quatro qualidades primeiras, e a desarmonia daí resultante tinha origem numa excessiva preponderância das qualidades quente e úmida. O calor e a umidade, em demasia relativa, conduziam à putrefação e desta nascia a peste. Estes dois excessos relativos podiam verificar-se: 1. nas qualidades do ar (causa exterior), principalmente em certas situações meteorológicas (intempéries), com relevo para estações do ano, horas do dia, pontos cardeais, direções do vento, etc.; 2. nas qualidades dos humores do organismo (causa interior), ferindo as suas vísceras; 3. conjuntamente, nas qualidades do ar e dos humores. Como decorrência desses fatores produzia-se, por extensão, a transformação da qualidade segunda: o cheiro, essência do ar corrupto ou pestenencial, que se cria manifestar internamente no corpo do doentes. Comprovando-o, a fetidez do hálito era prognóstico da contaminação do indivíduo.

Com base no princípio hipocrático do contraria contrariis curantur (ROQUE, 1979: 50), a profilaxia e a terapêutica incidiam na oposição às qualidades da doença, 
visando à restauração do equilíbrio natural; recorria-se às qualidades primeiras, seca e fria, e numa qualidade segunda que superasse o cheiro podre. Considerada a base galênica que orientava a concepção da doença expressa pela medicina de época, a sua ação se orienta em torno a três princípio básicos: circunscrever os sinais que indicam a proximidade da deflagração de um surto, as medidas profiláticas que se lhe anteponham e, por fim, o tratamento indicado aos epidemiados quando de sua ocorrência.

Quanto ao primeiro item, introduz o Regimento proueitoso... (JACOBI, 1962: 12), estando ausente da Recopilaçam das cousas... (ALVARES; CORONEL, MDLXXX) em função do contexto em que foi elaborada: grassava já a epidemia, concentrando-se, portanto, os esforços nas medidas voltadas à sua superação. Sete sinais prognosticam a proximidade da peste, ressaltando todos a qualidade do ar como fator determinante e, indicando a corrupção deste, a presença de moscas é sinal incisivo da deflagração de um surto. Em todos os outros, a qualidade alterada do ar se expressa na ação de forças cósmicas, como a passagens de cometas (referência aristotélica), relâmpagos e trovoadas, além da ação particularmente perniciosa do vento oriundo das regiões do meio-dia. É nesse nível que particularmente se expressa a relação entre o discurso médico e o religioso: segundo o autor do Regimento proueitoso... (JACOBI, 1962: 2), uma vez surgidos os sete sinais indicativos da doença, só a deliberação divina a poderia evitar.

No que se refere às causas da doença, o Regimento proueitoso... (JACOBI, 1962: 3-6) e a Recopilaçam das cousas... (ALVARES; CORONEL, MDLXXX: 2-5) se referem a três possíveis origens: a primeira, designada como de "raiz superior", concebia que certos fenômenos celestes, sob certas condições, atuavam sobre a Terra, dando origem a vapores que alteravam a qualidade úmida do ar e causavam, na extensão, a podridão e a peste. Decorre daí o conselho dos físicos a que fossem abandonados os lugares altos das moradias, mais propícios à ação direta das influências celestes. A segunda, da "raiz inferior", originava a peste do mal cheiro oriundo dos focos de podridão abundantes, tendo em vista as precárias condições de higiene dos meios urbanos (fator promotor da corrupção do ar). Quanto à última das suas origens, supostamente responsável pelos surtos mais violentos, derivava a peste da conjugação das duas "raízes" citadas, gerando uma extrema corrupção do ar. 
Destacada a corrupção do ar como fator da doença, o conceito de contágio vincula-se não fundamentalmente ao contacto interumano, embora também se expresse a esse nível, mas das distintas situações em que se convivia com o ar contaminado. Essa noção, crucial, articula todos os preceitos opostos à doença fixados pela medicina. Tanto ao nível geral quanto ao individual. O primeiro preceito, conselho básico, residia no afastamento máximo da fonte da doença, expressando-se no fugir o mais cedo possível, para local bem afastado, adiando-se ao máximo o retorno (ROQUE, 1979: 143). Aos que não podiam segui-lo, restava evitar ao máximo as situações de contato direto com o ar corrupto, respirando-o o menos possível, ou seja, evitando a fadiga oriunda de exercícios físicos, esforços violentos, a ira e os movimentos coléricos, que disritmando os movimentos respiratórios promovessem maior concentração de ar no peito.

Ambos os tratados destacam importância fundamental no que diz respeito à higiene urbana. Assim, na Recopilaçam das cousas... (ALVARES; CORONEL, MDLXXX: 4) prescreve-se a limpeza das ruas, praças e áreas coletivas com a máxima diligência e mais, que a sujeira acumulada nesse processo seja despejada em áreas distantes sobretudo a noite, evitando-se as horas de concentração da população. No intuito de recuperar a qualidade do ar, ambos convergem para a necessidade de se promover fogueiras com ervas aromáticas, visando, dessa forma, a superação da podridão e a purificação do ambiente. A introdução de gado vacum nas áreas infestadas cumpria o mesmo objetivo: cabia-lhes absorver todo o ar contaminado, o que era feito particularmente durante o sono, quando, segundo o Regimento proueitoso... (JACOBI, 1962: 6), o veneno adentrava o corpo. Feito isso, defumava-se as ruas e as casas, que também eram caiadas, completando-se a higienização das cidades.

Para preservar a qualidade do ar impunham-se práticas várias, tanto em nível individual quanto coletivo. Antes de mais nada, devia-se coibir qualquer situação da qual decorresse concentração humana, como bailes e festas e, particularmente, segundo a Recopilaçam das cousas... todo e qualquer ajuntamento de negros: "como pello mao cheiro que de si dão, E porq elles de si mesmos saõ mais prõptos a cair neste mal" (ALVARES; CORONEL, MDLXXX: 7). Mas o estigma social, expresso pelo discurso médico, não tinha um matiz apenas racial, posto que atingia às prostitutas (ALVARES; CORONEL, MDLXXX: 9), cujas casas mandavam encerrar, e ainda os pobres, que 
indicava, deviam ser recolhidos para evitar a sua livre circulação pela cidade, fontes que eram, também, da corrupção do ar (ALVARES; CORONEL, MDLXXX: 9).

Quanto ao isolamento nas endemias, as primeiras referências em Portugal datam do século XV. D. Duarte, no Leal Conselheiro, indicava às autoridades municipais a adoção de três medidas básicas, visando a impedir a disseminação local do contágio: em primeiro lugar, deviam expulsar das cidades os doentes, para que se curassem ou morressem fora do centro de habitação; quanto aos mortos, fossem enterrados em cemitérios extra-muros e, por fim, que suas casas fossem encerradas por quinze ou vinte dias (PIEL, 1942: 226). Medidas, ainda uma vez, fadadas a largo futuro e aprimoramento. No mesmo intuito, mas em sentido contrário, coibia-se o livre trânsito de pessoas oriundas de centros contaminados, o que pressupõe um sistema minimamente articulado de comunicação entre as regiões. A ordenação mais antiga nesse sentido conhecida em Portugal data do reinado de D. Afonso V. O ainda príncipe D. João ordenou à vila de Beja a instalação de quatro postos de fiscalização nas suas portas de entrada, limitando o ingresso apenas aos viajantes que jurassem ter deixado as áreas contaminadas há, no mínimo, trinta dias (TAVARES, 1987: 20). Em outubro de 1486, o então rei D. João II admoestou o concelho de Lisboa por ter permitido que ingressassem na cidade pessoas oriundas de Alhandra, onde então grassava a peste (TAVARES, 1987: 21). Sob D. João III, a medida assume foros de crime de "lesa majestade": o rei determinou, por carta régia de 3 de julho de 1531, que qualquer pessoa que fosse a Évora, onde estava a corte, oriunda de Lisboa ou de regiões impedidas, fosse sumariamente executada (OLIVEIRA, 1887: 455).

A partir de D. João II, o isolamento dos doentes tendeu a se circunscrever num local fixo, fechado e externo ao centro urbano. Em 1480, ordenou à cidade de Évora o estabelecimento do primeiro hospital especificamente destinado ao encerramento de epidemiados, que seriam assistidos por um físico pago pelo concelho (TAVARES, 1987: 24). Em 1485, despachou a liberação de uma quinta nos arredores de Lisboa para o mesmo fim (TAVARES, 1987: 25). D. Manuel, em um contexto em que a realeza assumia o campo da caridade pública, projetou para Lisboa o primeiro hospital permanente para pestosos, que seria construído em local isolado para "menos se conversarem os doentes com a cidade." (ROQUE, 1979: 186) D. João III, em carta resposta enviada à câmara de Coimbra, datada de 1 de setembro de 1525 , determinou a 
edificação urgente de um hospital, ao qual seriam recolhidos os pobres contaminados aos cuidados de um físico, de um cirurgião e de um barbeiro (CARVALHO, 1943: 33).

O caráter de segregação destas instituições revela-se da condição social dos internados e das precárias condições de suas instalações: em um hospital improvisado no Porto, em 1486, existiam apenas duas camas, ocupadas por seis a oito doentes que, rapidamente falecidos, davam lugar a outros tantos (ROQUE, 1979: 33). Segundo Eduardo Freire de Oliveira, quando não se instalavam os hospitais, o Provedor-Mor da Saúde determinava a reclusão dos "pobres" ("escrauos, e omees de soldada e obreiros dos macanicos") em suas ruas e bairros, que deviam ser vedados com cercas de tapumes, ao passo que a "gente grossa" permanecia em suas casas, sinalizadas pelos agentes da saúde (OLIVEIRA, 1887: 453).

A defesa contra pestes estrangeiras suscitou, no período, as primeiras medidas de polícia sanitária dos portos. D. João II esboçou, em 1492 (OLIVEIRA, 1887: 363), o primeiro regimento para o porto de Belém, em Lisboa. Determinou o balizamento de sua entrada, que serviria de marco obrigatório para a paragem de barcos oriundos de regiões contaminadas. Recolher-se-ia a população num alpendre isolado, sob quarentena, depositando-se as mercadorias num pontão, ao sol, para desinfestação. A demora na execução da obra levou o monarca a repreender o concelho da cidade em 1494. Contudo, durante as epidemias de 1492-1494, o concelho de Lisboa proibiu, por ordem régia (OLIVEIRA, 1887: 369), a atracação no porto de embarcações originárias da Alemanha e da França, e expulsou do Tejo naus fundeadas provenientes de Sevilha e da Andaluzia. Outro alerta preventivo foi expedido pela realeza aos portos costeiros em função da epidemia que, entre 1503 e 1504, assolou a Galiza. A vereação do Porto, a partir da ordem régia, proibiu a entrada de barcos oriundos daquela região, ordenando ainda aos pescadores galegos que se afastassem de seu porto (TAVARES, 1987: 23).

A reclusão dos doentes, base da política de segregação no tempo da epidemia, é referência básica nos manuais. Neste sentido, a Recopilaçam das Cousas... prescreve a construção de hospitais nos extremos da cidade para evitar a proximidade com ar corrupto que se concentra nesses locais. Nas casas em que se manifestasse a doença, o tratado prescreve que fossem isoladas e fechadas, não sem antes promoverem a sua desinfestação, através de fogos, perfumes e caiação de suas paredes (ALVARES; CORONEL, MDLXXX: 10). Também no tocante às normas de conduta individual, os 
regimentos médicos recomendam práticas diversas como, por exemplo, o evitar-se o banho diário, já que a umidade favorece a doença, limitando-se a higiene corporal à lavagem das mãos e do rosto com uma mistura de água e vinagre. Com relação à alimentação, o Regimento proueitoso..., seguindo indicação de Avicena, determina, em primeiro lugar, a moderação, já que a gula encheria o corpo de "maus humores" e esses seriam mais amiúde vítimas do "ar envenenado". No desjejum, convinha comer-se alimentos de gosto azedo, posto que fechavam os poros, impedindo a entrada no corpo do "ar corrupto" (JACOBI, 1962: 8).

Destaque-se ainda que o Regimento proueitoso... prescreve medidas importantes para a preservação do estado de espírito individual, afirmando que prazer e alegria eram indispensáveis à vida longa e, ao contrário, o receio da morte era agente favorecedor do contágio (JACOBI, 1962: 10). Recobrar e/ou manter a saúde, condição natural, exigia reintroduzir e/ou preservar o equilíbrio orgânico. Com base neste postulado define-se, nos textos, a ação primordial do médico, a de atuar em benefício da natureza, auxiliando-a no combate ao mal: "o principal que (o) medico he obrigado fazer, he imitar E ajudar a natureza”. (ALVARES; CORONEL, MDLXXX: 15) É nesse nível que reside tanto o argumento básico da afirmação da autoridade do discurso, quanto o da valorização da função social do físico. Regido, como a natureza, pela inteligência divina, cumpre-lhe circunscrever e defender o bem, ditando as regras de preservação da saúde da comunidade.

O tempo da epidemia é, portanto, o tempo fundamental da afirmação do saber médico, produtor de verdades sobre a doença, pretenso regulador de atos e condutas permitidas e proibidas. Seria interessante atentar, nesse sentido, para a produção nos dois tratados de um tempo específico e singular, que é paralelamente o da doença e o da efetivação do próprio discurso médico. Assim, ambos, discurso e doença, produzem-se numa relação dialética.

Mas, se a doença fornece a base para a afirmação desse discurso, sua trajetória aniquiladora impõe-lhe um desafio, admoestando-o com a chave de sua superação, aspecto que institui o paradoxo fundamental que o atravessa. Ao determinar a existência de um tempo singular e terrífico, porque submetido pelo mal e regido por interdições e rupturas obrigatórias nas relações sociais cotidianas - elemento indispensável à afirmação de seu poder discricionário e normatizador -, o discurso médico incidia sobre 
um fundo psicológico, reforçando o medo coletivo que abatia as populações. Impunhase-lhe, contudo, controlá-lo socialmente, posto que a sua exacerbação implicava, definitivamente, a negação do próprio discurso.

A autoridade de base requisitada pela medicina e disputada em meio a visões divergentes das causas, motivações e perspectivas de superação da doença, sorveu grande parte do seu fôlego e capacidade de afirmação pelo investimento do poder régio no seu afiançamento. Na medida em que a monarquia portuguesa chamou a si, ao menos desde princípios do seculo $\mathrm{XV}$, ainda sob D. João I, a responsabilidade por fixar as diretrizes e iniciativas a serem tomadas pelos concelhos urbanos em razão das epidemias - visando evitá-las e confrontá-las - as bases fundamentais da sua política decorreram direta e essencialmente das determinações emanadas da medicina de época, com destaque para as medidas de quarentena, de higiene urbana, de isolamento social, de reclusão de bairros e de ruas infectadas e de transferência obrigatória de doentes aos hospitais de epidemiados. Medidas extremas em muitos casos, contrapostas pela resistência das populações aterrorizadas pelos horrores que se faziam cotidianos e impunham uma radical e dolorosa ruptura dos laços sociais, chegavam mesmo a se fazerem draconianas, promovendo a suspeição generalizada entre vizinhos de ruas, bairros, cidades e mesmo reinos.

Sob D. João III, a cidade de Lisboa, foco central da intervenção régia que, como a doença, se disseminava pelo reino, recebeu o seu primeiro regimento de saúde, redigido pelo “doutor" Pero Vaz por ordem do soberano, em 1526. Dos seus artigos, destaca-se o projeto de intervenção máxima de um poder que se pretende absoluto - a vigilância do indivíduo - impondo-se sobre a "célula" básica do corpo social. No item terceiro, fixa penas pecuniárias, de açoite e degredo "aquelle que não declarar o doente que tiver em casa de qualquer doença que seja dentro em duas horas da hora em que adoecer [...]". (OLIVEIRA, 1887: 376) Se a reiteração frequente das determinações régias contra a doença ressaltam a oposição, mesmo que por inércia, à ação interventora do Estado pautada na medicina de época, as penalidades por ele impostas destacam o elemento crucial, favorecedor da supremacia do seu discurso: a ideologia por ele veiculada reforça-se no poder que ele detém e exerce.

Num reino assolado por epidemias, e esse um dos matizes do Portugal destes séculos, o físico, mais do que como um demiurgo, impõe-se como um guerreiro- 
servidor régio, aquele que em nome de El-Rei "peleja com tam bravo enemigo". (ALVARES; CORONEL, MDLXXX: 21) Afinal, não era a peste um dos quatro cavaleiros do Apocalipse? Foram os preceitos médicos, investidos pela realeza, que lançaram as bases do campo da saúde pública em Portugal desde a Idade Média. Quanto a esse "passado", tantas vezes rejeitado como abjeto, sua atual maior ignonímia parece consistir na angustiante sensação que nos impõe de que ainda possa estar, sob muitos aspectos, vivo e vigente, aqui e agora, entre nós... Logo entre nós que, de tão "avançados" nos imaginávamos ao abrigo das supostas misérias cotidianas pretéritas que afligiram nossos antepassados. Sob muitos aspectos, a Idade Média é aqui!

\section{Referências}

ABREU, Laurinda. A organização e regulação das profissões médicas no Portugal Moderno: entre as orientações da Coroa e os interesses privados. In: CARDOSO, Adelino; OLIVEIRA, António Braz de; MARQUES, Manuel Silvério (eds.). Arte Médica e Imagem do Corpo: de Hipócrates ao final do século XVIII. Lisboa: Biblioteca Nacional de Portugal, 2010, p. 97-122.

ALVARES, Thomaz; CORONEL, Garcia de Salzedo. Recopilaçam das cousas que convem guardarse no modo de preservar a Cidade de Lixboa: $E$ os sãos, $E$ curar os q estevere enfermos da peste (...). Lisboa: Typografia da Academia, 1801 (ed. conforme a de 1569).

BASTOS, Mário Jorge da Motta. O Poder nos Tempos da Peste (Portugal Séculos XIV/XVI). Niterói: Eduff, 2009.

BRAGA, Teófilo. Historia da Universidade de Coimbra nas suas relações com a instrucção publica portugueza. 1555 a 1700, vol. 2. Lisboa: Typographia da Academia Real das Sciencias, 1895.

BYRNE, Joseph P. Encyclopedia of the Black Death. California: ABC-CLIO, 2012.

CARVAlHO, J. B. (ed.). Cartas Originais dos Reis enviadas à Câmara de Coimbra (1480-1571). Coimbra: Biblioteca Municipal, 1943. 
CICCO, Camillo Di. Storia Della Peste da Morte Nera ad Arma Biologica. Roma: Create Space Independent Publishing Platform, 2014.

JACOBI, Johannes. Regimento Proueitoso contra ha pestenença. Porto: Livraria Civilização, 1962 (ed. fac-similada).

LE GOFF, Jacques (apres. de). As Doenças têm história. Lisboa: Editora Terramar, 1991.

MARQUES, A. H. de Oliveira. A Sociedade Medieval Portuguesa. Aspectos da Vida Quotidiana. Lisboa: Livraria Sá da Costa, 1987.

MEIRELlES, Antonio da Cunha Vieira de. Memorias de Epidemologia Portugueza. Coimbra: Imprensa da Universidade, 1866.

MOLLAT, Michel. Os Pobres na Idade Média. Rio de Janeiro: Campus, 1989.

OLIVEIRA, Eduardo Freire de. Elementos para a Historia do Municipio de Lisboa, tomo I. Lisboa: Typographia Universal, 1887.

PIEL, Joseph Maria (ed.). Leal Conselheiro de D. Duarte. Lisboa: Bertrand, 1942.

PORTUGAL, Alexandre A. das Neves. Advertencias dos meios que os Particulares podem usar para preservar-se da Peste... Lisboa: Typographia da Academia, 1801.

RAU, Virginia. Estudos de História Medieval. Lisboa: Editorial Presença, 1986.

ROQUE, Mario da Costa. As Pestes Medievais Européias e o "Regimento Proueytoso contra ha Pestenença”. Paris: Fundação Calouste Gulbenkian, 1979.

TAVARES, Maria José Pimenta Ferro. A Política Municipal de Saúde Pública (séculos XIV-XV). Revista de História Económica e Social, 19, 1987, p. 78-121. 